\title{
THE SYNDROME OF SHORT P-R INTERVAL, APPARENT BUNDLE BRANCH BLOCK, AND ASSOCIATED PAROXYSMAL TACHYCARDIA
}

\author{
BY
}

\section{ALASTAIR HUNTER, CORNELIO PAPP, AND JOHN PARKINSON}

From the Cardiac Department of the London Hospital

Received December 10, 1939

In 1930, Wolff, Parkinson, and White published the first collected series of eleven patients, who were apparently healthy but had electrocardiograms suggesting bundle branch block combined with a shortened $\mathrm{P}-\mathrm{R}$ interval. Most of them were subject to attacks of paroxysmal tachycardia and a few to paroxysms of auricular fibrillation. Isolated cases of this nature had been reported by Wilson (1915), Wedd (1921), and Hamburger (1929). Numerous authors since 1930 have added to the published cases and considered the mechanism of the syndrome. Our purpose is to review present opinion, to report further cases, and to examine the various hypotheses advanced in explanation.

The electrocardiographic features are as follows. With a rate that is normal, $\mathrm{P}$ is upright, and the iso-electric segment from the end of $\mathrm{P}$ to $\mathrm{R}$ is abolished, so that the ventricular complex starts immediately after $\mathbf{P}$ or even overlaps the end of it, reducing the distance from the onset of $P$ to the onset of $R$ (the $\mathrm{P}-\mathrm{R}$ interval) to less than $0.12 \mathrm{sec}$. The ventricular complex resembles that of bundle branch block; it is widened beyond 0.10 sec., often slurred in its ascent, and notched near its summit. The R-T period may be depressed or elevated, seldom assuming the full diphasic character of ordinary branch block. A surprising fact is that these patients may at other times show a normal electrocardiogram (Fig. 1), or even alternating normal and abnormal complexes without any change in rate (Fig. 2). The records during the paroxysms of tachycardia are generally of supraventricular type.

Of these three important features-a short P-R interval, ventricular complexes of bundle branch block type, and paroxysmal tachycardia-the first is a constant finding, the second may be absent in certain cases that are included on other grounds, and the third occurs in the great majority.

The lability of the Sh.P-R : B.B.B.* rhythm should not lead to confusion with paroxysmal bundle branch block (Comeau, Hamilton, and White, 1935 ; Bishop, 1935) in which there is a normal $\mathbf{P}-\mathbf{R}$ interval, an abnormal QRS only

* Abbreviations are not free from criticism, but in this case it seems reasonable to the authors and editor to use $S h . P-R: B . B . B$. for the short $\mathrm{P}-\mathrm{R}$ interval with bundle branch block complexes. 


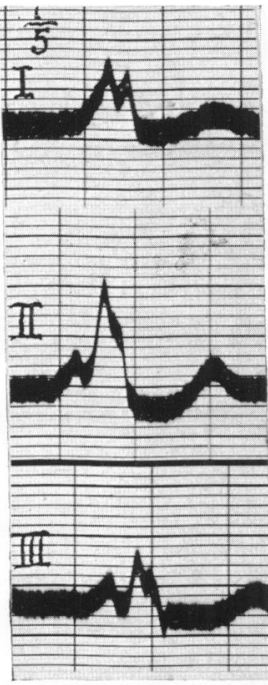

A

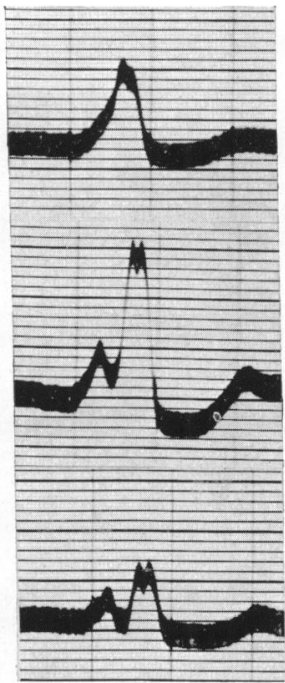

B

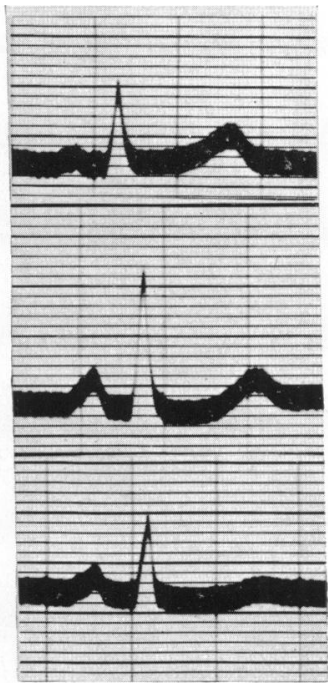

C

Fig. 1.-Electrocardiograms appearing spontaneously at different times in Case 1.

(A) and (B) Sh.P-R : B.B.B. of different aspects. (C) Physiological.

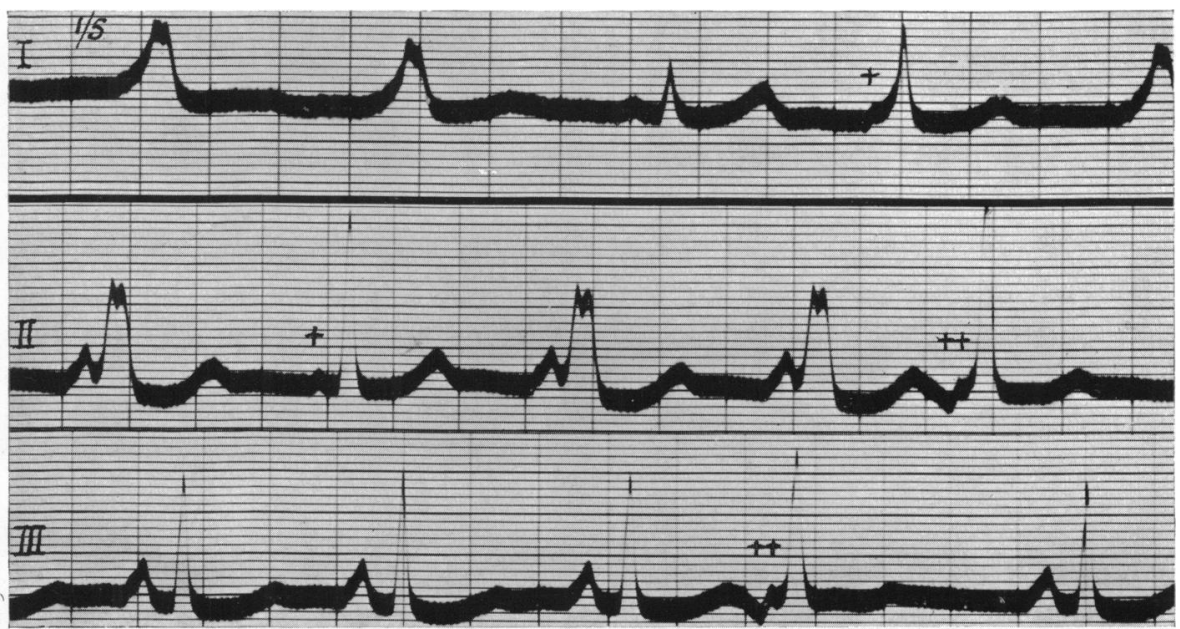

Fig. 2.-Electrocardiogram of Case 1, showing bundle branch block and physiological complexes occurring spontaneously. In addition, nodal beats $\left(^{+}\right)$appear in leads $I$ and II, and nodal extra-systoles $\left({ }_{-+}^{+}\right)$in leads II and III.

above a certain ventricular rate, an associated myocardial defect, and an absence of paroxysmal tachycardia.

\section{Method OF INVESTIGATION}

The series comprises 22 patients of whom 19 show the fully developed syndrome of $S h . P-R: B . B . B$, while the remaining 3 show a $S h . P-R$ interval only, and are included because they are related. The general incidence of the 
syndrome, the state of the heart, the frequency and duration of the paroxysmal attacks, and the prognosis were investigated clinically. The conditions influencing the reversion of the electrocardiogram from the Sh.P-R :B.B.B. type to the physiological type were studied by graphic methods, especially in six favourable cases.

\section{Clinical Analysis}

Incidence.-The full Sh.P-R : B.B.B. syndrome is uncommon, for a search has found no more than 90 reported cases ; the largest series was that of 11 cases by Wolff, Parkinson, and White (1930). With the 19 cases of our own, the total now reaches about 109 . The rarity of the syndrome is also apparent from the fact that among 19,000 electrocardiograms in the Cardiac Department of the London Hospital the syndrome was found only three times ; and among 14,000 in a consulting practice only eight times. These 8 cases constitute 5.7 per cent. of 140 consecutive bundle branch block cases, and 5.3 per cent. of 150 consecutive cases of paroxysmal tachycardia. The only symptom that may be attached to the syndrome is the occasional palpitation due to paroxysmal tachycardia. Otherwise it is only recognized on routine electrocardiographic examination. If paroxysmal tachycardia does occur, several examinations at other times may be necessary for its recognition, as a normal cardiogram does not exclude the appearance of $S h . P-R: B . B . B$. on other occasions. It is thus likely that some cases escape recognition. The youngest recorded in our series is 16 years ; the case of a boy aged 4 years has been described (Hamburger, 1929), and that of another boy of 14 , who had been subject to paroxysmal tachycardia since he was 2 years old (Wolferth and Wood, 1933). Our oldest patient is 59 , and the oldest reported is 62 years.

Associated Heart Disease.-The statement made by Wolff, Parkinson, and White (1930) that the syndrome affected people who were otherwise healthy was supported by nearly all subsequent writers, although in fact 18 of the 90 reported cases had signs of heart disease that was regarded as incidental (Wolferth and Wood, 1933 ; Cossio, Berkonsky, and Kreutzer, 1936 ; Holzmann, 1937 ; Fernbach, 1937 ; Hartog, 1938 ; Fischer, 1938 ; Gruber, 1938). These included hypertension, mitral stenosis, aortic incompetence (syphilitic and rheumatic), and coronary thrombosis. In 6 of these 18 there is reason to think that the heart disease had some bearing on the occurrence of the syndrome. Fulchiero (1935), Katz and Kaplan (1938), found Sh.P-R : B.B.B. after coronary thrombosis. In the thyrotoxic patient of Master, Jaffe, and Dack (1937) the Sh.P-R : B.B.B. disappeared after thyroidectomy. Bain and Hamilton (1926) recorded a characteristic curve in a case of rheumatic carditis without any valvular lesion. In one of Gruber's (1938) patients the abnormality was detected during a severe throat infection ; and a patient of Wilson's (1934) showing it died during a prolonged paroxysm of tachycardia, and necropsy revealed myocardial changes.

In our series only three showed certain signs of organic heart disease (Table I). The first paroxysm immediately followed a first attack of rheumatic fever 
in a patient with aortic incompetence (Case 7) ; it came 15 years after such an attack in another with aortic incompetence and mitral stenosis (Case 10). A third never had paroxysms, but he first showed the characteristic electrocardiogram immediately after an attack of rheumatic fever that did not otherwise affect his heart (Case 12). One had hypertensive heart failure, but never paroxysmal tachycardia (Case 13). Another had no other abnormal heart signs when examined, yet according to his doctor he died one year later of congestive heart failure (Case 15). A sixth had his first paroxysm during lobar pneumonia (Case 17), a seventh had a positive Wassermann (Case 18), and an eighth with a short P-R interval only and no paroxysmal attacks had thyrotoxicosis (Case 22). Two others had a double first sound (Cases 19 and 20). Thus in about a third of our series some evidence of myocardial damage was obtained, but as no full necropsy reports are yet available, its importance cannot be assessed. Ordinary paroxysmal tachycardia with a normal cardiogram between attacks is comparable in that the patient is generally free from detectable organic heart disease, though in a proportion it does result from cardiac damage.

TABLE I

Clinical Features of Patients with Sh.P-R : B.B.B. Syndrome

\begin{tabular}{|c|c|c|c|c|c|}
\hline \multirow{2}{*}{$\begin{array}{l}\text { Case } \\
\text { No. }\end{array}$} & \multirow{2}{*}{$\begin{array}{c}\text { Sex and } \\
\text { Age }\end{array}$} & \multicolumn{2}{|c|}{ Time in years } & \multirow{2}{*}{$\begin{array}{l}\text { Duration of } \\
\text { Paroxysms }\end{array}$} & \multirow{2}{*}{$\underset{\text { Heart* }}{\text { Remarks on }}$} \\
\hline & & $\begin{array}{c}\text { Under } \\
\text { Observation }\end{array}$ & $\begin{array}{l}\text { Liability to } \\
\text { Paroxysms }\end{array}$ & & \\
\hline $\begin{array}{l}1 \\
2 \\
3 \\
4 \\
5 \\
6 \\
7 \\
8 \\
9 \\
10 \\
11 \\
12 \\
13 \\
14 \\
15 \\
16 \\
17 \\
18 \\
19\end{array}$ & $\begin{array}{ll}\text { F. } & 54 \\
\text { F. } & 17 \\
\text { M. } & 19 \\
\text { F. } & 51 \\
\text { F. } & 37 \\
\text { F. } & 48 \\
\text { M. } & 51 \\
\text { M. } & 49 \\
\text { M. } & 35 \\
\text { M. } & 24 \\
\text { F. } & 20 \\
\text { M. } & 16 \\
\text { M. } & 58 \\
\text { F. } & 35 \\
\text { M. } & 54 \\
\text { M. } & 45 \\
\text { M. } & 44 \\
\text { M. } & 53 \\
\text { M. } & 47\end{array}$ & $\begin{array}{c}5 \\
6 \\
3 \\
6 \\
14 \\
1 \\
1 / 12 \\
4 \\
11 \\
1 / 12 \\
8 / 12 \\
10 \\
1 / 12 \\
4 \\
1 \\
1 \\
8 \\
5 / 12 \\
14\end{array}$ & $\begin{array}{c}26 \\
2 \\
\frac{18}{18} \\
\frac{31}{36} \\
11 \\
16 \\
1 / 12 \\
5 \\
- \\
-3 \\
20 \\
27 \\
3 \\
2 \\
30\end{array}$ & $\begin{array}{l}2-4 \text { hours } \\
2-48 \text { hours } \\
1-8 \text { hours } \\
1-7 \text { days } \\
12-24 \text { hours } \\
\text { up to } 5 \text { days } \\
\text { minutes } \\
1 \text { day } \\
15-30 \text { min. } \\
- \\
3 \text { hours } \\
1-12 \text { hours } \\
1-8 \text { hours } \\
30 \text { min. } \\
8 \text { hours } \\
\text { minutes }\end{array}$ & $\begin{array}{l}\overline{-} \\
\overline{-} \\
\overline{-} \\
\text { Rh.A.I. } \\
\overline{-} \\
\text { A.I. and M.S. } \\
\text { R.F. } \\
\text { B.P. } 240 / 130 \\
\text { Died } \\
\text { Pneumonia } \\
\text { W.R. }++ \\
\dagger\end{array}$ \\
\hline $\begin{array}{l}20 \\
21 \\
22\end{array}$ & $\begin{array}{ll}\text { M. } & 33 \\
\text { F. } & 35 \\
\text { F. } & 41\end{array}$ & $\begin{array}{c}\text { Short } P-R \\
8 / 12 \\
\text { Once } \\
\text { Once }\end{array}$ & $\begin{array}{c}\text { Vormal Ventr } \\
2 \\
-\end{array}$ & $\begin{array}{l}\text { Complexes } \\
\text { 5-30 min. } \\
-\end{array}$ & ${ }_{\text {Th. }}^{\dagger}-$ \\
\hline
\end{tabular}

* Except as stated in the last column, there were no symptoms or signs of cardiovascular disease apart from those of the syndrome ; see text above for explanation of the symbols. $\dagger$ Double first sound.

Liability to Paroxysms.-This is greater in patients with Sh.P-R :B.B.B. than in those with $S h . P-R$ only. Four of the former group and two of the 
latter group gave no history of paroxysms. There is some evidence that the presence of associated heart disease makes paroxysmal tachycardia less likely. Two of the four examples of Sh.P-R :B.B.B. without paroxysms were Case 13 with hypertensive heart failure and Case 12 with $S h . P-R: B . B . B$. consequent upon a rheumatic attack. The three cases described by Fulchiero (1935), by Master, Jaffe, and Dack (1937), and by Katz and Kaplan (1938), with severe myocardial damage were similarly free from paroxysms. On the other hand, two of our series (Cases 3 and 5), like two others reported by Newman (1931) and by Eckey and Schäfer (1938), had no other evidence of heart disease and yet they were not subject to paroxysmal tachycardia. Incidentally, the paroxysms in patients with Sh.P-R :B.B.B. seem to present no unusual features (Table I).

Prognosis.-This is obviously of great importance in view of the admitted seriousness of bundle branch block in general. Wolff, Parkinson, and White (1930) regarded the syndrome as benign, and all other authors have followed this view with the single exception of Wilson (1937), who saw a patient with it die in a paroxysm of tachycardia. Of our own patients-some observed for several years-one died of congestive heart failure, two had and still have valvular disease, and one could not be traced. The remainder are alive and well and free from cardiac symptoms except during the paroxysms of tachycardia, which, however, continue to recur sometimes with more and sometimes with less frequency. This confirms the original belief in its comparative innocence. Admittedly the syndrome may be produced occasionally by cardiac disease, but even here the prognosis rests upon the nature and degree of the causal lesion.

This favourable prognosis may lead to confusion with the right bundle branch conduction defect first described by Wilson, Johnston, Hill, Macleod, and Barker (1934), and later by William Evans (1937), of which the benign character has been stressed by Wood, Jeffers, and Wolferth (1935). This has nothing more in common with $S h . P-R: B . B . B$., which is indeed better entitled to the term benign.

\section{ElECTROCARDIOGRAPHIC ANALYSIS}

In six of the cases of Sh.P-R:B.B.B., and in one of Sh.P-R with normal ventricular complex, the electrocardiogram was found on other occasions to be physiological. This variation was spontaneous in six cases of Sh.P-R : B.B.B., in two of which it could also be produced by exertion, and in one also by atropin (1/50 gr. subcutaneously). Both exertion and atropin produced a physiological curve in one case of $S h . P-R$ with normal ventricular complex (Table II).

In four other cases, however, atropin failed, although in one of them spontaneous reversion was observed. The other tests such as unilateral or bilaterial carotid compression, deep or held respiration, the Valsalva test, and amyl nitrite failed to alter the records. Atropin proves to be an unreliable method of producing reversion, as already stated by Pezzi (1931) and others. 
The gradual transition produced by atropin, when it is effective, may, however, shed light on the underlying mechanism.

TABLE II

Patients showing Both Normal and Bundle Branch Block Complexes

\begin{tabular}{|c|c|c|c|c|c|}
\hline \multirow{2}{*}{$\begin{array}{l}\text { Case } \\
\text { No. }\end{array}$} & \multicolumn{3}{|c|}{ Change from Sh.P-R : B.B.B. to Normal } & \multicolumn{2}{|c|}{ Shape of $P$} \\
\hline & Spontaneous & After exercise & After atropin & Sh.P-R : B.B.B. & Normal \\
\hline 1 & + & + & + & \multirow{6}{*}{\multicolumn{2}{|c|}{$\begin{array}{l}\text { Peaked } \\
\text { No difference. } \\
\text { Peaked } \\
\text { No difference. } \\
\text { Both rounded but of different } \\
\text { shape. } \\
\text { Both peaked but of different } \\
\text { shape. }\end{array}$}} \\
\hline 2 & + & + & - & & \\
\hline 3 & + & - & - & & \\
\hline 4 & + & - & - & & \\
\hline 5 & + & - & - & & \\
\hline 18 & + & - & - & & \\
\hline $20^{*}$ & - & + & + & $\begin{array}{c}\text { Inverted and } \\
\text { peaked in lead I. }\end{array}$ & $\begin{array}{l}\text { Rounded and } \\
\text { upright in lead I. }\end{array}$ \\
\hline
\end{tabular}

* Change only from Sh.P-R to normal P-R.

The records of Case 1 show spontaneous variations between Sh.P-R : B.B.B. and normal complexes (Fig. 1), and in certain portions nodal beats and nodal extrasystoles are also seen (Fig. 2). In this patient atropin was used twice. On the first occasion bundle branch block complexes similar to those of Fig. 1A were present, and 20 minutes after the injection a different branch block complex appeared, similar to those of Fig. 1B. At the same time $P$ changed in shape (Fig. 3A), the original sharp peaked wave giving place to a broad and

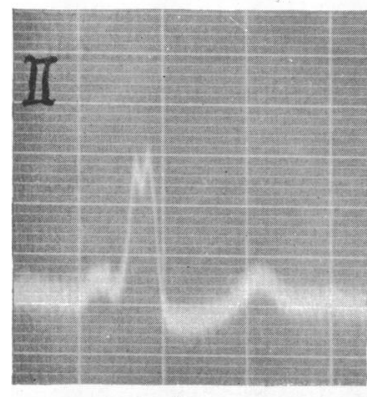

A

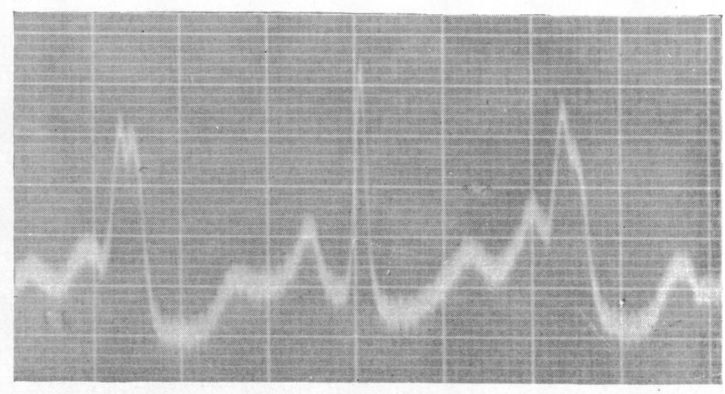

B

FIG. 3.-Case 1, (A) 20 minutes, (B) 50 minutes after atropin (gr. 1/50 subcut.).

(A) Complex of Fig. 1 (B) type preceded by rounded P.

(B) Complexes of Fig. 1 (B), (C), and (A) type appearing successively.

rounded one. Fifty minutes after the injection each type of complex appeared one after another (Fig. 3B). On the second occasion, two months later, complexes similar to those shown in Fig. 1B were constantly present. After atropin (25 minutes) the notch in $\mathrm{R}$ gradually disappeared and $\mathrm{P}$ assumed the rounded form of Fig. 3A ; then physiological complexes followed (Fig. 4). 
Finally a gradual return to the original branch block complexes of Fig. 1B type was recorded, and it was complete 80 minutes after the injection. During

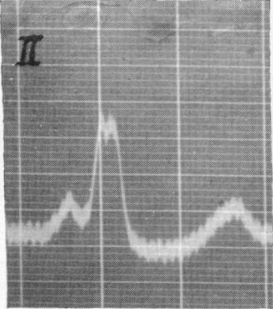

A

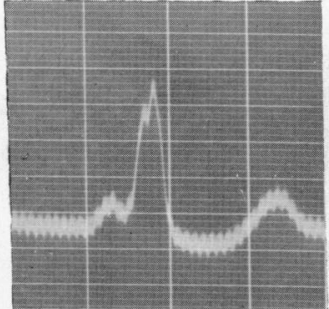

$\mathrm{B}$

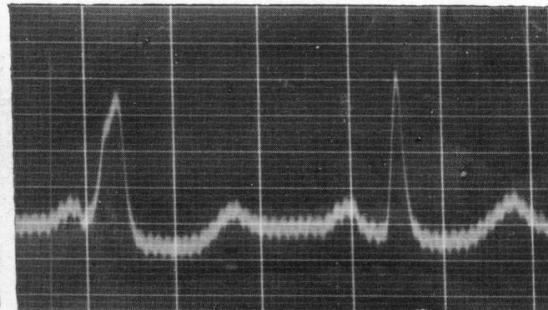

$\mathrm{C}$

Fig. 4.-Case 1, one month later.

(A) Before, (B) and (C) 25 minutes after atropin, showing a gradual transition from Sh.P $-R$ : B.B.B. (Fig. 1B type) to physiological complexes.

both experiments with atropin, nodal beats as well as nodal extrasystoles with inverted $\mathbf{P}$ and supraventricular complexes similar to those in Fig. 2 were often seen.

Such simultaneous changes in P and QRS occurred in Cases 3, 5, and 18, spontaneously. On one occasion complexes suggestive of an intermediate stage

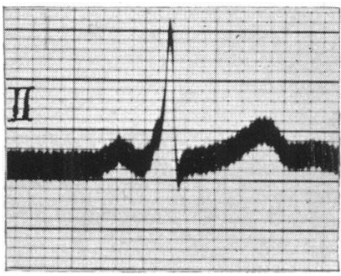

A

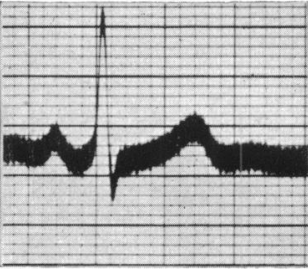

B

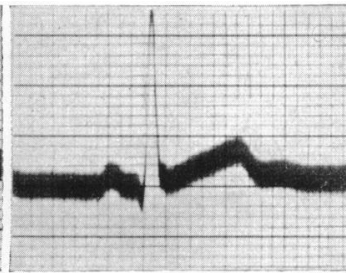

C

FIG. 5.-Case 3 showing spontaneously (A) Sh.P-R : B.B.B., (B) transition complex, and (C) a physiological complex ; each type of complex is preceded by a different $P$.

between the Sh.P-R:B.B.B. and the physiological complexes were seen, and they were preceded by $P$ waves of different shapes (Fig. 5).

In Case 20, an example of Sh.P-R and normal ventricular complex, the $P$ wave changed shape with restoration of a normal $P-R$ interval (Fig. 6).

These observations show that in four out of six cases of Sh.P-R :B.B.B. the reversion of the abnormal to the normal ventricular complex was accompanied by a change in the $P$ wave. Under atropin, a gradual change in the shape of $P$ accompanied a gradual change in the QRS complex (Fig. 4).

The electrocardiograms during paroxysms of tachycardia were available in seven cases. In five, supraventricular tachycardia was recorded, in one supraventricular and ventricular tachycardia, and in the remaining one auricular fibrillation and "ventricular" tachycardia.

Identification of the electrocardiogram of the syndrome rests upon the combination of a short $\mathbf{P}-\mathbf{R}$ interval with a ventricular complex similar to branch block (i.e. Sh.P-R:B.B.B.). Where the $\mathrm{P}-\mathrm{R}$ interval varies in the 
different leads, difficulty may arise. In Fig. 7 the P-R interval is $0 \cdot 10 \mathrm{sec}$. in lead I with a ventricular complex of $0 \cdot 10 \mathrm{sec}$., while in lead II $\mathrm{P}-\mathrm{R}$ is $0 \cdot 16 \mathrm{sec}$. and QRS is $0.08 \mathrm{sec}$. ; in lead III also it is probably normal. To decide which limb lead gives the truest $\mathbf{P}-\mathbf{R}$ indicative of auriculo-ventricular conduction; chest leads were employed. With the exploring electrode in the fifth interspace on the right sternal border and the distal electrode on the right arm, as used by Zàrday (1937) for the right auricle, we took records in six healthy students. The $\mathrm{P}-\mathrm{R}$ interval in this chest lead was identical with $\mathrm{P}-\mathrm{R}$ in leads II
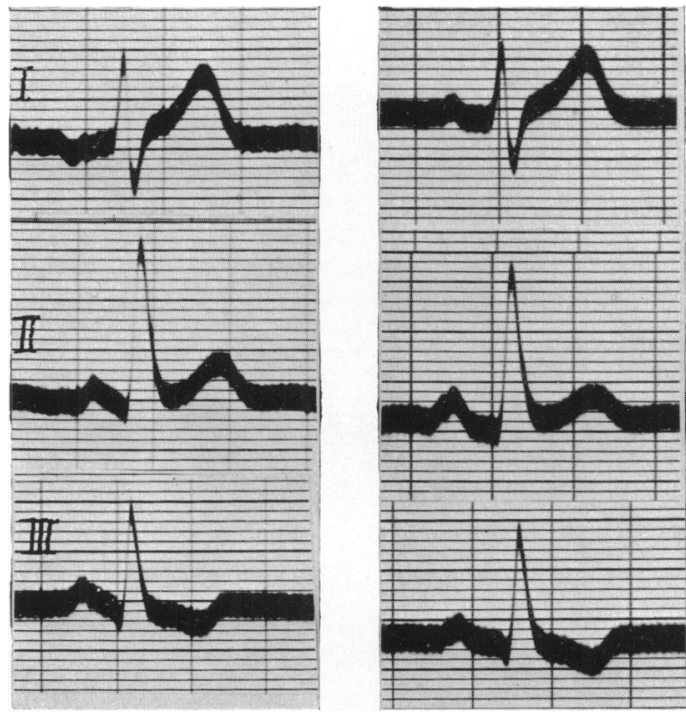

Fig. 6.-Case 20 with Sh.P-R interval only.

(A) Before and (B) 50 minutes after atropin : not on $\mathrm{v}$ $P_{1}$, previously inverted, but also $P_{2}$ and $P_{3}$ change their shape with return to normal A-V conduction.

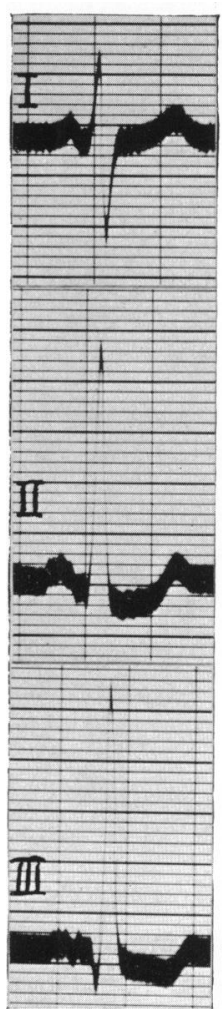

FIG. 7.

(See text.)

and III, but longer than that in lead I where the first part of $P$ is so often isoelectric ; and as in lead III P may be inverted or diphasic, the $\mathrm{P}-\mathrm{R}$ interval in lead II is the best measure of the A-V conduction. If so, the P-R interval in Fig. 7 is normal and the record is not an example of the syndrome.

In the following three (Cases 19, 8, and 12) doubt might arise whether they should be included in the syndrome or not. Although the characteristic Sh.P-R and modified QRS occur clearly in lead II in one (Fig. 8A), in lead I in another (Fig. 8B), and in leads I and II in the third (Fig. 8C), the other leads might be passed as normal or uncertain. Yet we have no doubt both from the general aspect of the records and from the accompaniment of paroxysmal tachycardia that all three are genuine examples of the syndrome. The 
" iso-electric" P-R interval includes a slight curve (Fig. $8 \mathrm{~A}$ and B), or a notch (Fig. 8C) representing the initial part of the QRS complex.

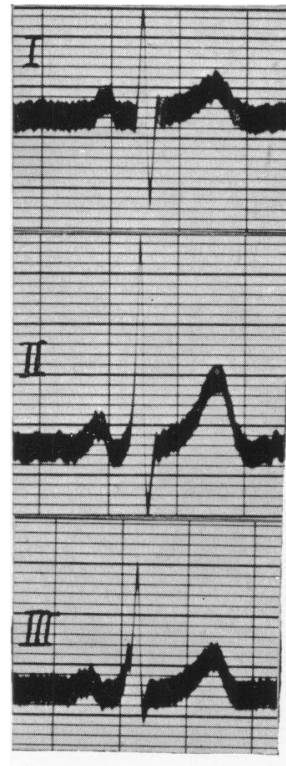

A

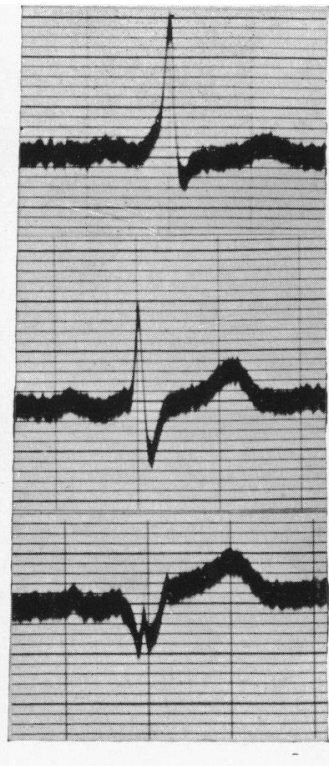

B

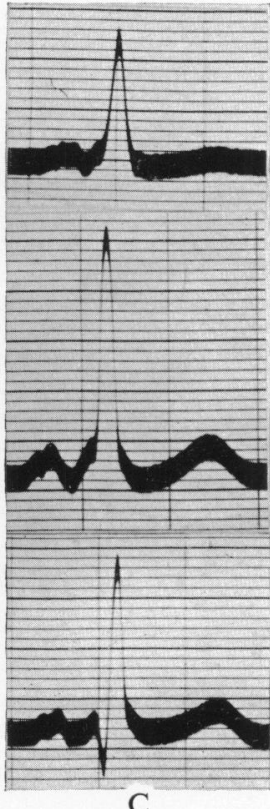

$\mathrm{C}$

FIG. 8.-Electrocardiograms in three patients with Sh.P-R :B.B.B.

(A) Case 19, (B) Case 8, and (C) Case 12. The characteristic slurring with Sh.P-R interval appears in leads I and III of (A), in lead II of (B), and in lead III of (C), as a modified almost iso-electric $\mathbf{P}-\mathbf{R}$ period.

\section{Previous Hypotheses}

No satisfactory explanation for the mechanism of the syndrome seems to have been given, no method of reproducing the abnormality in experiment is known, and no post-mortem study of any established clinical case has been published. An attempt has been made in Table III to classify the various hypotheses advanced.

Wolff, Parkinson, and White (1930) regarded it as true bundle branch block resulting from some abnormal vagal effect which at the same time accelerated $\mathrm{A}-\mathrm{V}$ conduction ; in one case removal of vagal control by exercise or by atropin converted the abnormal complex into a normal one. Pezzi (1931) disagreed, maintaining that vagal release was often ineffective, and postulated a paranodal pacemaker due to an irritative lesion near the A-V node, affecting conduction to one ventricle only. Sigler (1933) reported cases in which branch block appeared when the $\mathrm{R}-\mathrm{T}$ interval was shorter than a certain critical length, but normal when it was of greater length ; he therefore assumed that it represented fatigue of the conducting system. Hauss and Schütt (1938) accepted Condorelli's belief in both sino-auricular and sino-nodal pathways, and imagined a simultaneous block of the S-A pathway and of one bundle branch. Thus a Sh.P-R might be produced from a more direct impulse along the sino-nodal route and be accompanied by branch block. 


\section{TABLE III}

Current Explanations of Bundle Branch Block with a Short P-R Interval

I. Hypotheses accepting it as True Bundle Branch Block.

(1) With sinus pacemaker :

(a) Abnormal vagal influence (Wolff, Parkinson, and White, 1930 ; Wilson, 1915).

(b) Fatigue of conductive system (Sigler, 1933).

(c) Block of S-A pathway and of one bundle branch (Hauss and Schütt, 1938).

(2) With abnormal pacemaker :

Paranodal rhythm and block of one bundle branch (Pezzi, 1931; Wedd, 1921 ; Tung, 1936 ; Katz and Kaplan, 1938).

II. Hypotheses rejecting it as True Bundle Branch Block.

(1) Ventricular asynchronism due to premature stimulation of one ventricle :

(a) By bundle of Kent (Holzmann and Scherf, 1932 ; Wolferth and Wood, 1933 ; Scherf and Schönbrunner, 1935 ; Roberts and Abramson, 1936 ; Zàrday, 1938 ; Holzmann, 1937 ; Fernbach, 1937).

(b) By increased conductivity of A-V node and one bundle branch (Fulchiero, 1935 ; Spangenberg, Vedoya and Gonzalez, 1937 ; Hartog, 1938).

(c) By increased conductivity of one bundle branch with nodal rhythm (Pines, 1938).

(d) By mechanical excitation from the auricle of an irritative focus in one ventricle (Holzmann and Scherf, 1932 ; Cossio, Berkonsky, and Kreutzer, 1936).

(e) By ventricular extrasystole interfering with a normal sinus beat (Moia and Inchauspe, 1938).

(2) Abnormal ventricular complex due to an electrical event during the iso-electric $\mathbf{P}-\mathbf{R}$ period :

(a) Auricular extrasystole (Gruber, 1938).

(b) Electrical event resulting from persistent (fœtal) conducting fibres (Eckey and Schäfer, 1938).

That there is no true branch block is the opinion of numerous writers, especially Holzmann and Scherf (1932) and Wolferth and Wood (1933). They found that the P-T interval was within the limit of normal ventricular conduction, contrary to the rule in true bundle branch block. Further they found the same P-T interval in both normal and abnormal complexes where both were present in the same patient. In these papers it is assumed that there is an accessory pathway of A-V conduction, such as was described by Kent (1892), and that this pathway may function ; this in their opinion would easily explain the Sh.P-R and the premature excitation of one ventricle simulating branch block. The paroxysms of tachycardia were ascribed by Wolferth and Wood to a retrograde conduction at a favourable moment giving rise to a circus movement. Normal conduction and normal curves appeared when the sinus impulses reached a certain rate - a rate beyond the conductivity of the bundle of Kent.

Other authors have also rejected branch block as an explanation. Fulchiero (1935) and others (see Table III) suggested that there was an increased conductivity of the specific system, notably of the A-V node and of one branch of the bundle. Pines (1938) invoked a similar state in one bundle branch, but explained the $S h . P-R$ as consequent upon a nodal rhythm. Cossio, Berkonsky, and Kreutzer (1936), accepting the suggestion of Holzmann and Scherf (1932), believed that a normal auricular contraction mechanically stimulated an excitable focus in one ventricle, from which a $S h . P-R$ and also an abnormal ventricular complex resulted.

Still opposing the hypothesis of a true bundle branch block, other authors speak of an abnormal electrical activity during the iso-electric P-R period. 
Gruber (1938), using auricular leads, regarded the normal $P$ as quickly followed by an auricular extrasystole that deformed the ascending limb of $R$ so that branch block was imitated. Eckey and Schäfer (1938) assumed the persistence of embryonic conducting fibres in the auricles, so that the normal $\mathbf{P}$ was immediately succeeded by a bizarre ventricular complex.

Bearing upon the mechanism of the syndrome we have also consulted Elliott and Nazum (1932), C. Evans (1937), Sprague (1937), Ritter (1939) ; and on the electrocardiographic aspect Herzum (1934), Dressler (1937), Bishop (1937), Arana and Cossio (1938), and Campbell and Elliott (1939). Under war conditions we have been unable to examine the paper of Teràn (1938).

\section{Discussion}

Any hypothesis explaining the mechanism of this syndrome must deal first with the site of the pacemaker, and secondly with the diffusion (or conduction) of the impulse. The fact that during a reversion of Sh.P-R:B.B.B. to normal the $P$ wave often changes in shape is strongly against the view that in both conditions the impulse arises in the sinus node. The gradual change of $P$ coincident with gradual changes in the ventricular complex, as here described, makes the use of an accessory pathway (such as Kent's) unlikely, though that is how Holzmann and Scherf (1932), Wolferth and Wood (1933), and others have tried to explain it. With the bundle of Kent in operation the shape of the $\mathbf{P}$ wave should be identical before both abnormal and normal complexes (Wolferth and Wood, 1933). But as stated by Pines (1938) and even in the cases recorded by Scherf and Schönbrunner (1935) and by Zàrday (1938)—partisans of the bundle of Kent-changes in the shape of $P$ on reversion to normal are evident ; and they are present in some of the records of Fernbach (1937), Chen Lang Tung (1936), Moia and Inchauspe (1938). With an alternative route along a bundle of Kent, there should be two distinct curves and no intermediate ones, but there were intermediate ventricular complexes in the cases of Wilson (1915) and Chen Lang Tung (1936), and in four of our own. As the P of the normal and of the branch block complex are often different, the sinus pacemaker cannot be in sole control.

Pezzi's (1931) explanation of an abnormal pacemaker near the A-V node would fit in with the change in $\mathrm{P}$ with change in complex. Even an upright $\mathrm{P}$ in all leads does not exclude this hypothesis (Holzmann and Scherf, 1933), and the liability to paroxysms might be expected with an irritative lesion involving the A-V node. Yet the coexistent bundle branch block can scarcely be explained in this way.

Leaving the subject of the $\mathrm{P}$ wave, the ventricular complex looks like a branch block, but is it one ? The appearance has been ascribed to conduction by the bundle of Kent, to increased conductivity in one bundle branch, or to a premature excitation of one ventricle. All three ideas connote asynchronism of the two ventricles, which is also inseparable from true bundle branch block. Ventricular asynchronism is said to be present by Wolferth and Wood (1933) Scherf and Schönbrunner (1935), and Moia and Inchauspe (1938). Others 
(Battro, Braun-Menendez and Orias, 1937 ; Spangenberg, Vedoya and Gonzalez, 1937 ; Braun-Menendez and Solari, 1939) deny ventricular asynchronism in the syndrome. Triple rhythm is an uncertain sign of asynchronism ; it was noted in only 1 of our 19 cases, an infrequency contrary to the experience of Wolferth and Wood (1933).

A second objection to the existence of a real branch block is the fact that the $\mathbf{R}-\mathrm{T}$ interval with change to normal complexes remains almost unaffected. In contrast the $\mathrm{R}-\mathrm{T}$ interval in cases of paroxysmal branch block increases with onset of branch block by at least $0.05 \mathrm{sec}$. (Table IV). On the left are the six cases of our own where a change to normal complexes took place, and on the right one case of our own (K) and nine cases from Comeau, Hamilton, and White (1935), in which fairly exact measurements were possible.

A third objection is the difference in form between the curves of true bundle branch block and those found in this syndrome. The features of Sh.P-R :B.B.B. are these. The very beginning of the ventricular complex is slurred in one or more leads, though sometimes the slurring appears almost iso-electric in other leads where it looks like a normal P-R interval succeeded by a normal ventricular complex (Fig. 8). The slurring more often involves the foot of the ascending limb of $\mathrm{R}$, giving the most characteristic appearance of all (Fig. 1, 5A, and $8 \mathrm{~A}, \mathrm{~B}$, and $\mathrm{C}$ ), very different from true branch block as we think. Another distinguishing feature is the form of the $S-T$ and the $T$ of the complex. Even when $\mathbf{R}$ or $\mathbf{S}$ is large and emphatic, it is seldom followed immediately by any big swing in the opposite direction ; indeed, a $\mathrm{T}$ approximating to normal is the rule. The characteristic diphasic appearance of the pathological branch block is seen only in about 10 per cent. of the Sh.P-R : B.B.B. cardiograms.

TABLE IV

The R-T Interval in Sh.P-R : B.B.B. and in Paroxysmal Bundle Branch Block

\begin{tabular}{|c|c|c|c|c|c|}
\hline \multicolumn{3}{|c|}{ Cases of this Series } & \multicolumn{3}{|c|}{ Cases of Comeau, Hamilton, and White } \\
\hline \multirow{2}{*}{$\begin{array}{l}\text { Case } \\
\text { No. }\end{array}$} & \multicolumn{2}{|c|}{$\begin{array}{l}\text { Short P-R with Bundle Branch } \\
\text { Block }\end{array}$} & \multirow{2}{*}{$\begin{array}{l}\text { Case } \\
\text { No. }\end{array}$} & \multicolumn{2}{|c|}{ Paroxysmal Bundle Branch Block } \\
\hline & $\begin{array}{l}\mathrm{R}-\mathrm{T} \text { in Normal } \\
\text { (sec.) }\end{array}$ & $\begin{array}{l}\mathrm{R}-\mathrm{T} \text { in B.B.B. } \\
(\mathrm{sec} .)\end{array}$ & & $\begin{array}{l}\mathbf{R}-\mathrm{T} \text { in Normal } \\
\text { (sec.) }\end{array}$ & $\begin{array}{l}\mathrm{R}-\mathrm{T} \text { in B.B.B. } \\
(\mathrm{sec} .)\end{array}$ \\
\hline $\begin{array}{r}1 \\
2 \\
3 \\
4 \\
5 \\
18\end{array}$ & $\begin{array}{l}0.38 \\
0.40 \\
0.40 \\
0.34 \\
0.33 \\
0.33\end{array}$ & $\begin{array}{l}0.38 \\
0.40 \\
0.42 \\
0.36 \\
0.36 \\
0.33\end{array}$ & $\begin{array}{r}2 \\
3 \\
4 \\
6 \\
8 \\
9 \\
10 \\
11 \\
12 \\
\mathrm{~K}\end{array}$ & $\begin{array}{l}0 \cdot 28 \\
0 \cdot 35 \\
0 \cdot 37 \\
0 \cdot 35 \\
0 \cdot 33 \\
0 \cdot 31 \\
0 \cdot 37 \\
0.35 \\
0 \cdot 33 \\
0 \cdot 40\end{array}$ & $\begin{array}{l}0.33 \\
0.40 \\
0.42 \\
0.40 \\
0.36 \\
0.36 \\
0.42 \\
0.43 \\
0.39 \\
0.45\end{array}$ \\
\hline Average & 0.363 & 0.375 & Average & 0.344 & 0.396 \\
\hline
\end{tabular}


Taken together, the doubt about ventricular asynchronism, the lack of change in the R-T distance on reversion to normal, the peculiar shape of the very first part of the ventricular complex, and the rarity of the gross diphasism of ordinary branch block, invalidate the true branch block hypothesis. The last two hypotheses in Table III, like those already discussed, fail to explain the gradual change in the $\mathrm{P}$ wave and the ventricular complex (Fig. 4).

From our own findings we are of opinion that any hypothesis should explain the following features :

1. The difference in the shape of $\mathrm{P}$ before normal and Sh.P-R :B.B.B. complexes.

2. The peculiar shape of the ventricular complex compared with that of ordinary branch block.

3. The gradual change of $\mathrm{P}$ and $\mathrm{QRS}$ from Sh.P-R :B.B.B. to normal (after atropin), and the appearance of intermediate ventricular complexes (Fig. 4).

Since previous explanations did not meet these points, we began to formulate the view of a double rhythm composed of two interfering pacemakers. The idea was that a nodal beat might be superimposed upon a normal PQRST complex, so that the $\mathrm{P}-\mathrm{R}$ interval was shortened by the early ventricular complex of the nodal beat, which was then succeeded by the normal ventricular complex, the two in juxtaposition giving a broad wave simulating branch block. Such a conception was encouraged when we found that a complex, such as the second in Fig. 2 (lead II), imposed upon a normal complex, such as Fig. 1C (lead II), gave a resultant complex not unlike that of the syndrome. The idea was abandoned because it is difficult to believe that two supraventricular impulses, each passing down the whole of the bundle system, could follow one another so closely in time ; the first impulse must leave behind it a refractory period which would bar the passage of the second.

Such a difficulty might be overcome by assuming that a beat arising near the normal pacemaker (for the $\mathbf{P}$ is altered) is interfered with by a ventricular extrasystole arising prematurely low in one bundle branch. This is not unlike the view of Moia and Inchauspe (1938) who proposed a similar " mixed" rhythm as a modification of the purely extrasystolic hypothesis of Holzmann and Scherf (1932) and Cossio, Berkonsky, and Kreutzer (1936). Graphic evidence of interference between a sinus and a ventricular beat is given by Wenckebach and Winterberg (1927 ; Fig. $189 \mathrm{D}$ and E) though in paroxysmal tachycardia. In our view the upper impulse would spread only to the ventricle other than that producing the extrasystole. If it did so spread, it might modify the diphasism of the extrasystolic complex, especially in its S-T portion, and shorten it. Normal complexes would appear after sudden suppression of the low ventricular centre, transition complexes during its gradual suppression following vagal release by atropin. The frequency of paroxysmal tachycardia in these patients points to hyperexcitability of the conducting tissue. The absence of ventricular extrasystoles in our own cases is an objection to the kind of interference which we have suggested. Though not advancing this view as a complete solution of the 
problem, the idea of a double rhythm at a normal rate, in contrast to that of true bundle branch block, seems to us the best explanation of our findings.

A short $\mathbf{P}-\mathbf{R}$ interval with normal ventricular complex probably represents true nodal rhythm, as recognized by Pezzi (1931), Scherf and Schönbrunner (1935), and Clerc, Levy, and Cristesco (1938). It may be stable, as in our Cases 21 and 22, or unstable, as in Case 20, and it may or may not be accompanied by liability to paroxysmal tachycardia.

\section{SUMmary AND CoNCLUSIONS}

1. Nineteen patients having an electrocardiogram with a short $\mathbf{P}-\mathbf{R}$ interval and a ventricular complex of bundle branch block appearance (Sh.P-R : B.B.B.) -the so-called Wolff, Parkinson, White syndrome-have been studied, along with three others having a short $\mathrm{P}-\mathrm{R}$ interval but a normal ventricular complex.

2. The Sh.P-R:B.B.B. syndrome constitutes about 5 per cent. of all cases of bundle branch block (140 consecutive cases), and it is found in about 5 per cent. of patients who are subject to paroxysmal tachycardia (150 consecutive cases). About three quarters (15 out of 19) of those with Sh.P-R : B.B.B. had attacks of paroxysmal tachycardia, but only one of the three with $S h . P-R$ alone had attacks. The characteristic electrocardiogram may be discovered at a routine examination in persons otherwise healthy, in patients with paroxysms of tachycardia, or in those having some other cardiac disease.

3. Much as in ordinary paroxysmal tachycardia, where most patients are otherwise healthy though some have associated and even causal heart disease, so in this $S h . P-R: B . B . B$. syndrome only a minority have organic heart disease (18 of 90 reported cases and 3 of our 19 cases). Occasionally the causal connection seems to be definite ; for instance one patient first showed the characteristic cardiogram soon after acute rheumatism ; and examples have been reported after coronary thrombosis. The prognosis seems to be unaffected by the occurrence of the syndrome, even in a patient with associated heart disease.

4. A remarkable feature is that the same patient may at one time show the typical cardiogram and at another a normal one, both at normal rates. Such switching may be spontaneous, though it may also be induced by exertion or by atropin. It is usually abrupt ; only if produced by atropin is it likely to be gradual. The paroxysms of tachycardia are generally supraventricular. Of seven patients whose paroxysms were recorded, five proved to be supraventricular, one supraventricular and at other times ventricular, and one ventricular tachycardia with auricular fibrillation.

5. A partially iso-electric $P$ in lead $I$ of a normal tracing with full ventricular complex (near $0.1 \mathrm{sec}$.) might simulate $S h . P-R: B . B . B$., except that the other leads are normal. On the other hand the slurring of $\mathrm{R}$ in a case of Sh.P-R : B.B.B. may in one lead fuse with the $\mathrm{P}-\mathrm{R}$ period making it iso-electric, and like a normal beat, although the other leads are characteristic of the syndrome.

6. Bearing on the mechanism of the peculiar electrocardiogram : (a) $\mathrm{P}$ often becomes modified in shape when the abnormal cardiogram of Sh.P-R :B.B.B. 
changes to normal, and this fact alone shows the involvement of a pacemaker that under both conditions can scarcely be a normal one ; $(b)$ fixity of the $\mathrm{R}-\mathrm{T}$ distance with reversion to normal, and the peculiar aspect of the apparent branch block (slurring of the foot of $\mathrm{R}$ and rarity of diphasism compared with true branch block) are reasons against acceptance of the syndrome as real bundle branch block.

7. As these current hypotheses scarcely explain our findings, we incline to think that the typical syndrome represents a double rhythm by two interfering pacemakers, one near the sinus and the other in one bundle branch. The modified $\mathrm{P}$ preceding the broad ventricular complexes is due to the upper pacemaker ; a ventricular extrasystole, arising low in one bundle, quickly interferes and so shortens the P-R interval. The aberrant QRS complex is produced by the ventricular extrasystole and is modified by the QRS of the S-A impulse which reaches the ventricle through the unaffected bundle branch. Intermediate ventricular complexes might be due to the gradual suppression of the ventricular pacemaker. The increased excitability of the conductive system (possibly congenital), responsible for the two pacemakers at a normal rate, is also indicated by the special liability to paroxysmal tachycardia. The subsidiary group, that with short $\mathbf{P}-\mathrm{R}$ only, are examples of true nodal rhythm.

We wish to thank Sir Maurice Cassidy, Dr. Crighton Bramwell, Dr. Maurice Campbell, Dr. K. D. Wilkinson, Dr. J. W. Linnell, Dr. Lisle Punch, Dr. Almond, and Surgeon Commander Nesbitt, R.N., for their kindness in allowing us to make use of their cases, and also Dr. William Evans who gave us special facilities for observations upon one of his. We are grateful to Dr. Phillip Hallock of New York for his generosity in sending his detailed records of a remarkable case. Dr. John Grimshaw was good enough to revise the text. Dr. Alan N. Drury, F.R.S., has kindly helped us with the physiological aspects.

\section{REFERENCES}

Arana, R., and Cossio, P. (1938). Rev. argent. Cardiol., 5, 43.

Bain, C. W. C., and Hamilton, C. K. (1926). Lancet, 1, 807.

Battro, A., Braun-Menendez, E., and Orias, O. (1937). Rev. argent. Cardiol., 3, 325.

Bishop, L. F. (1937). Amer. J. med. Sci., 194, 794. (1938). Amer. Heart J., 15, 354.

Braun-Menendez, E., and Solari, O. (1939). Arch. intern. Med., 63, 830.

Campbell, M., and Elliott, G. A. (1939). Brit. Heart J., 1, 123.

Clerc, A., Levy, R., and Cristesco, C. (1938). Arch. Mal. Cour, 31, 569.

Comeau, W. J., Hamilton, J. G. M., and White, P. D. (1938). Amer. Heart J., 15, 276.

Cossio, P., Berkonsky, J., and Kreutzer, R. (1936). Rev. argent. Cardiol., 2, 411.

Dressler, W. (1937). Klinische Elektrokardiographie, 4th ed., Vienna and Berlin.

Eckey, P., and Schäfer, E (1938). Arch. Kreislaufforsch., 2, 388.

Elliott, A. H., and Nazum, F. R. (1932). Amer. Heart J., 7, 680.

Evans, C. (1937). Amer. Heart J., 14, 753.

Evans, W. (1937). Lancet, 2, 1127 and 1184.

Fernbach, J. (1937). Orv. Hetil., 81, 377.

Fischer, R. (1938). Arch. Mal. Cour, 31, 997.

Fulchiero, A. (1935). Minerva med., 1, 310.

Gruber, Z. (1938). Z. Kreislaufforsch., 30, 100.

Hamburger, W. W. (1929). Med. Clin. N. Amer., 13, 343.

Hartog, P. (1938). Nederl. Tijidschr. Geneesk, 82, 42, 5115.

Hauss, W., and Schütt, B. (1938). Z. klin. Med., 133, 665.

Herzum, K. (1934). Orv. Hetil., 78, 1111.

Holzmann, M. (1937). Arch. Kreislaufforsch., 1, 2.

- and Scherf, D. (1932). Z. klin. Med., 121, 404.

Katz, N., and Kaplan, L. G. (1938). Amer. Heart J., 16, 694.

Kent, A. F. S. (1892). J. Physiol., 14, 23.

Master, A. M., Jaffe, H. E., and Dack, S. (1937). Mount Sinai Hosp. J., 4, 100. 
Moia, B., and Inchauspe, L. (1938). Rev. Argent. Cardiol., 5, 114.

Newman, M. (1931). Brit. med. J., 2, 1134.

Pezzi, C. (1931). Arch. Mal. Coeur, 24, 1.

Pines, I. (1938). Wien. Arch. inn. Med., 32, 129.

Ritter, H. (1939). Z. Kreislaufforsch., 31, 206.

Roberts, G. H., and Abramson, D. I. (1936). Ann. intern. Med., 9, 983.

Scherf, D., and Schönbrunner, E. (1935). Z. klin. Med., 128, 750.

Sigler, L. H. (1933). Amer. J. med. Sci., 185, 211.

Spangenber, J. J., Vedoya, R., and Gonzalez, V. J. (1937). Rev. argent. Cardiol., 4, 244.

Sprague, H. B. (1937). International Clinics, 47, 187.

Teràn, V. S. (1938). Rev. méd. de Rosario, 28, 1191.

Tung, C. (1936). Amer. Heart J., 11, 89.

Wedd, A. M. (1921). Arch. intern. Med., 27, 571.

Wenckebach, K. F., and Winterberg, H. (1927). Die unregelmässige Herztätigkeit, Leipzig. Wilson, F. N. (1915). Amer. J. med. Sci., 16, 1008.

(1938). Recent Progress in Electrocardiography and the Interpretation of Borderline Electrocardiograms, New York.

, Johnston, F. D., Hill, I. G. W., MacLeod, A. G., and Barker, P. S. (1934). Amer. Heart J., 9, 459.

Wolferth, C. C., and Wood, F. C. (1933). Amer. Heart J., 8, 297.

Wolff, L., Parkinson, J., and White, P. D. (1930). Amer. Heart J., 5, 685.

Wood, F. C., Jeffers, W. A., and Wolferth, C. C. (1935). Amer. Heart J., 10, 1056.

Zàrday, I. (1937). Z. Kreislaufforsch., 29, 208.

- (1938). Z. Kreislaufforsch., 30, 509. 